SANDIA REPORT

SAND97-2631 • UC-704

Unlimited Release

Printed November 1997

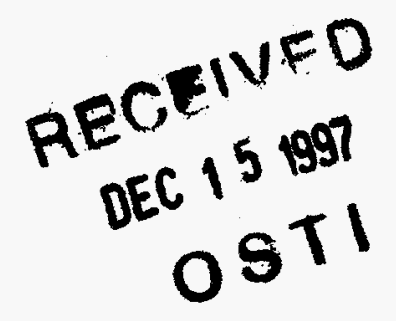

\title{
Viscosities of Epoxy Encapsulants
}

\author{
ph

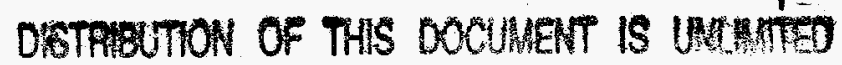

Douglas Adolf, Roger Strommen, Harry Johnson

Prepared by

Sandia National Laboratories

Albuquerque, New Mexico 87185 and Livermore, California 94550

Sandia is a multiprogram laboratory operated by Sandia Corporation, a Lockheed Martin Company, for the United States Department of Energy under Contract DE-AC04-94AL85000.

Approved for public release; further dissemination unlimited,

\section{Sandia National Laboratories}


Issued by Sandia National Laboratories, operated for the United States Department of Energy by Sandia Corporation.

NOTICE: This report was prepared as an account of work sponsored by an agency of the I Jnited States Government. Neither the United States Government nor any agency thereof, nor any of their employees, nor any of their contractors, subcontractors, or their employees, makes any warranty, express or imolied, or assumes any legal liability or responsibility for the accuracy, completeness, or usefulness of any information, apparatus, product, or processi disclosed, or represents that its use would not infringe privately owned rights. Reference herein to any specific commercial product, process, or selvice by trade name, trademark, manufacturer, or otherwise, does not necesisarily constitute or imply its endorsement, recommendation, or favoring by the United States Government, any agency thereof, or any of their contractors or subcontractors. The views and opinions expressed herein do not aecessarily state or reflect those of the United States Government, any agercy thereof, or any of their contractors.

Printed in the United States of America. This report has been reproduced directly from the best available copy.

Available to DOE and DOE contractors from

Office of Scientific and Technical Information

P.O. Box 62

Oak Ridge, TN 37831

Prices available from (615) 576-8401, FTS 626-8401

Available to thi public from

National Technical Information Service

U.S. Department of Commerce

5285 Port Royal Rd

Springfield, VA 22161

NTIS price sodes

Printed cop, $7:$ A03

Microfiche copy: A01 


\section{DISCLADMER}

Portions of this docoment may be illegible in electronic image products. Images are produced from the best available original docoment 


\title{
Distribution Category UC-704
}

\author{
SAND 97-2631 \\ Unlimited Release \\ Printed November 1997
}

\section{Viscosities of Epoxy Encapsulants}

Douglas Adolf, Roger Strommen, and Harry Johnson Theoretical and Computational Materials Modelling Department Sandia National Laboratories

P.O. Box 5800

Albuquerque, NM 87185-0333

\begin{abstract}
The temperature, curing, and filler dependencies of the viscosities of common epoxies used at Sandia as encapsulants are presented along with examples of useful applications.
\end{abstract}




\section{Introduction}

Whereas much effort has been expended over the years to measure the thermophysical properties of solid epoxy encapsulants for stress calculations, little characterization of the liquid epoxies has been attempted. Such characterization could be applied to optimization of processing time/temperature schedules, simulation of mold filling to eliminate void formation, or prediction of filler settling during cure. Moreover, this liquid characterization is non-trivial due to the numerous dependencies we need to investigate. For example, processing typically occurs from temperatures of 65 to $95^{\circ} \mathrm{C}$ over which the viscosity can change by a factor of 7 . More dramatic is the change in viscosity with filler level, where addition of $45 \mathrm{vol} \%$ alumina can increase the viscosity by a factor of 70 and even induce non-Newtonian behavior. Most dramatic, however, is the dependence on state of cure, since at the gel point, the viscosity diverges. In the following report, formalisms are documented that capture these dependencies, and common Sandia epoxies are characterized.

Shell Epon 828, the digylcidyl ether of bisphenol A and the only epoxy resin used in these studies, was cured with either diethanolamine (DEA) or Shell Curing Agent " $Z$ " (a mixture of aromatic amines) and filled with glass microballoons (GMB), tabular alumina (Alox), $\beta$-eucryptite ( $\beta$-eu), or rubber toughener (C.TBN). All chemicals and fillers, curing and processing schedules, storage and handling procedures, and stoichiometric ratios followed those detailed in current process specifications. All rheological measurements on unfilled samples were performed with cone-and-plate fixtures while filled sample measurements employed Couette geometry. Parallel or cone-and-plate geometries yielded spurious results in filled systems due to particulate settling or flotation. A Rheometrics RFS-II was used for all testing. 


\section{Temperature Effects}

The temperature dependent viscosities of $828,828 / \mathrm{DEA}, 828 / \mathrm{Z}$, and 828/CTBN are shown in Fig. 1 and given in Table 1.

Table 1

\begin{tabular}{|c|c|c|c|c|}
\hline temp (C) & $\underline{828(\mathrm{P})}$ & 828/DEA (P) & $\underline{828 / Z(P)}$ & $\underline{828 / C T B N(P)}$ \\
\hline 20 & 120 & & & \\
\hline 25 & 50.0 & & & 242 \\
\hline 30 & 22.0 & 490 & 50.0 & 121 \\
\hline 35 & 12.0 & & & 65.0 \\
\hline 40 & 6.50 & 100 & 11.0 & 35.0 \\
\hline 45 & 4.00 & & & \\
\hline 50 & 2.50 & 23.0 & 3.40 & 13.0 \\
\hline 55 & 1.65 & & & \\
\hline 60 & 1.10 & 7.00 & 1.25 & 6.00 \\
\hline 65 & 0.80 & & & \\
\hline 70 & 0.60 & 2.60 & 0.55 & 3.00 \\
\hline 75 & 0.44 & & & \\
\hline 80 & 0.34 & 1.25 & 0.26 & 1.50 \\
\hline 85 & 0.27 & & & \\
\hline
\end{tabular}

All data can be reduced by the familiar "WLF" equation

$$
\log \frac{\eta(T)}{\eta\left(T_{o}\right)}=\frac{-C_{1}\left(T-T_{o}\right)}{C_{2}+T-T_{o}}
$$

where the required parameters are given in Table 2 below.

Table 2

$\begin{array}{lcccc}\text { system } & \underline{\mathrm{C}}_{1} & \underline{\mathrm{C}_{2}\left({ }^{\circ} \mathrm{C}\right)} & \underline{\mathrm{T}}_{\mathrm{O}}\left({ }^{\circ} \mathrm{C}\right) & \underline{\eta\left(\mathrm{T}_{\mathrm{O}}\right)(\mathrm{P})} \\ 828 & 3.09 & 119 & 70 & 0.60 \\ 828 / \mathrm{DEA} & 4.65 & 123 & 70 & 2.60 \\ 828 / \mathrm{Z} & 4.28 & 127 & 70 & 0.55 \\ 828 / \mathrm{CTBN} & 4.19 & 125 & 70 & 3.00\end{array}$


Fig. 1: Temperature Dependence of Epoxy Resins

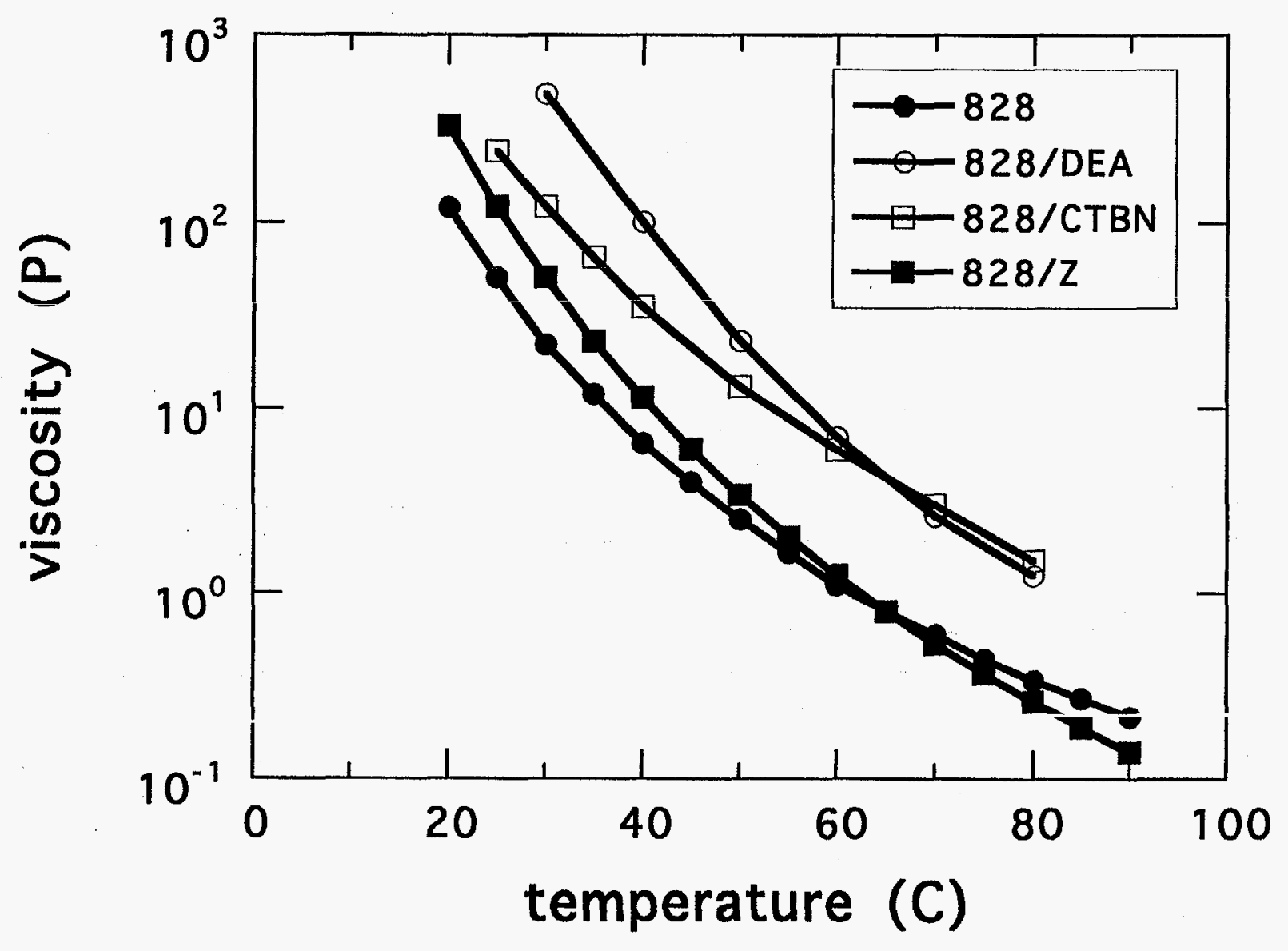


The $828 / D E A$ and $828 / Z$ systems are reactive so the viscosities naturally increase with time. The temperature dependence for $Z$ given here describes the "initial" viscosity immediately after mixing. The situation for $828 / \mathrm{DEA}$ is more complicated since the 828 and DEA are actually immiscible immediately after mixing as seen by the cloudy appearance. Only after the reactive DEA amino-hydrogen has endcapped the 828 does the system clear and become homogeneous. We call this preliminary reaction "adduct formation". The temperature dependence given in Table 2 describes the 828/DEA viscosity immediately after adduct formation, but before any true crosslinking reaction takes place.

\section{Chemistry Effects}

\section{A. DEA adduct formation}

Describing the viscosity increase during DEA adduct formation is important since mixing, degassing, and even pouring may be performed during this period. We first must determine the increase in extent of reaction, p, with time for isothermal cures. Fig. 2 shows the adduct reaction rate for isothermal cures at 70,80 , and $90 \mathrm{C}$ as measured by differential scanning calorimetry (DSC). These data can be fit moderately well by a rate equation of the form

$$
\frac{\mathrm{dp}}{\mathrm{dt}}=\left(2 \times 10^{9} \mathrm{~min}^{-1}\right) \mathrm{e}^{-(15,100 \mathrm{cal} / \mathrm{mole}) / \mathrm{RT}} \mathrm{p}^{0.5}(1-\mathrm{p})^{1.5}
$$

The heat of reaction was found to be $90 \mathrm{~J} / \mathrm{g}$.

Fig. 3 shows the increase in steady shear viscosity during these cures measured independently using cone-and-plate fixtures. And in Fig. 4, the viscosity is crossplotted against the extent of reaction integrated from the DSC data. Even in Fig. 4, we do not see universal behavior since the 


\section{reaction rate}

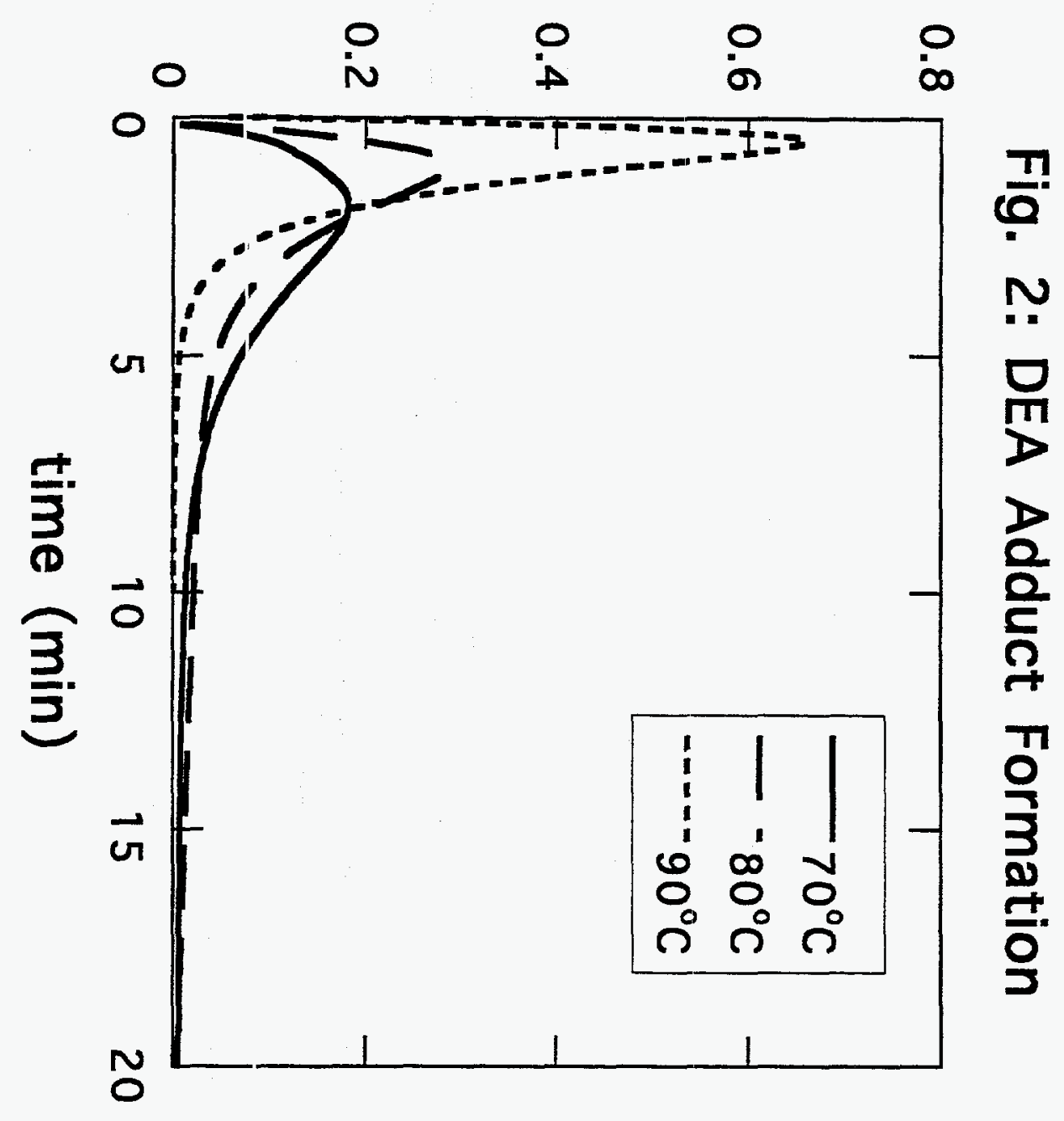




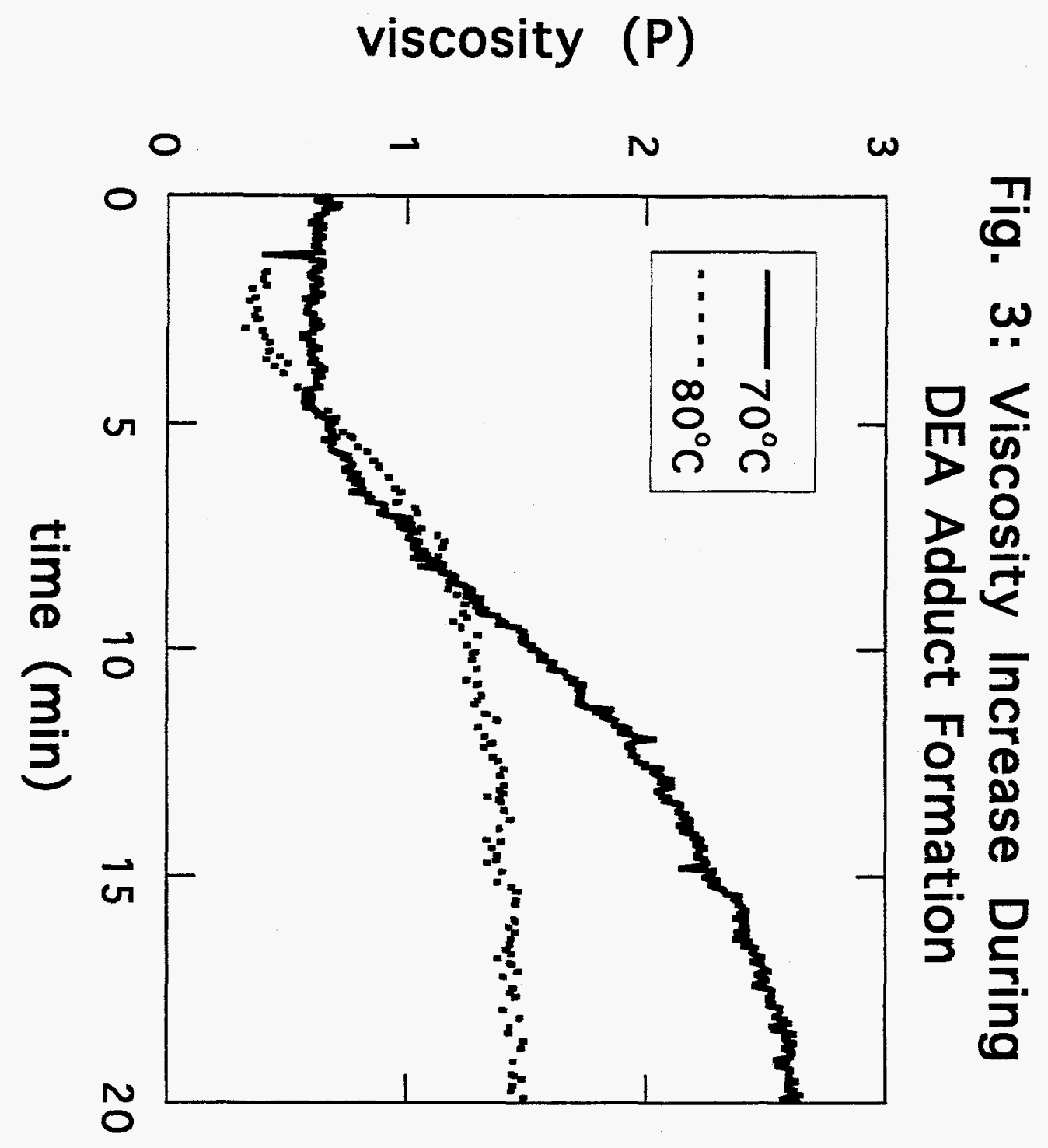


Fig. 4: Viscosity Dependence Upon Extent of Reaction

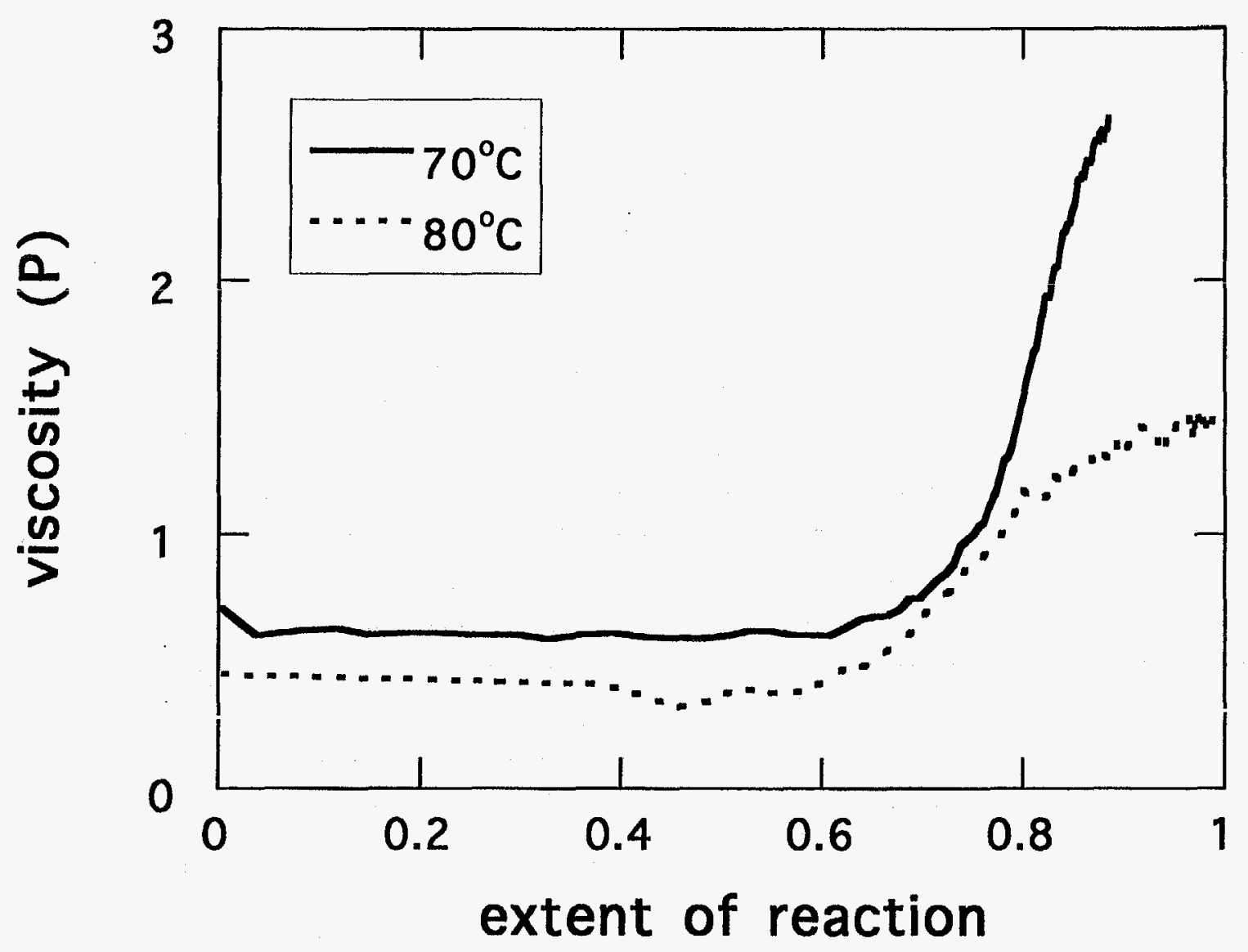


viscosities at the beginning, $\eta_{0}$, and end, $\eta_{\infty}$, of adduct formation are temperature dependent. [ $\eta_{\infty}$, here, would be equivalent to the temperature-dependent 828/DEA viscosity of Table 1.] Therefore, in Fig. 5, we plot the normalized viscosity defined as

$$
\frac{\eta-\eta_{0}}{\eta_{\infty}-\eta_{0}}
$$

against the extent of reaction and obtain a fairly universal curve. Note that the viscosity does not rise smoothly with extent of reaction, but appears to increase sharply only after most $(\sim 70 \%)$ of the adduct reaction has been completed. This almost discontinuous behavior may be due to the fact that the initial reaction bath is actually two-phase and much of the adduct formation may occur at the interface of these phases. If so, this intitial reaction would only tend to enlarge the "DEA balls" which, in turn, would not grossly affect the viscosity. However, near adduct completion, the DEA is chemically solubilized, the reaction bath becomes one-phase, and the viscosity could increase significantly.

\section{B. Gelation}

We previously have intensively studied and documented the evolution of viscoelasticity during the crosslinking of these epoxies ${ }^{1}$ and so will only briefly review it here. A consistent theoretical framework can be established based on two experimentally validated premises: (1) the evolution of network structure follows percolation predictions and (2) the individual chain dynamics are "Rouse-like" [i.e. behave as a system of beads and springs]. The theory predicts that the viscosity increases as

$$
\eta(p, T)=\eta\left(0, T-T_{g}\right) \varepsilon^{-4 / 3}
$$


Fig. 5: Universal Relationship Between Reduced Viscosity and Extent of Reaction

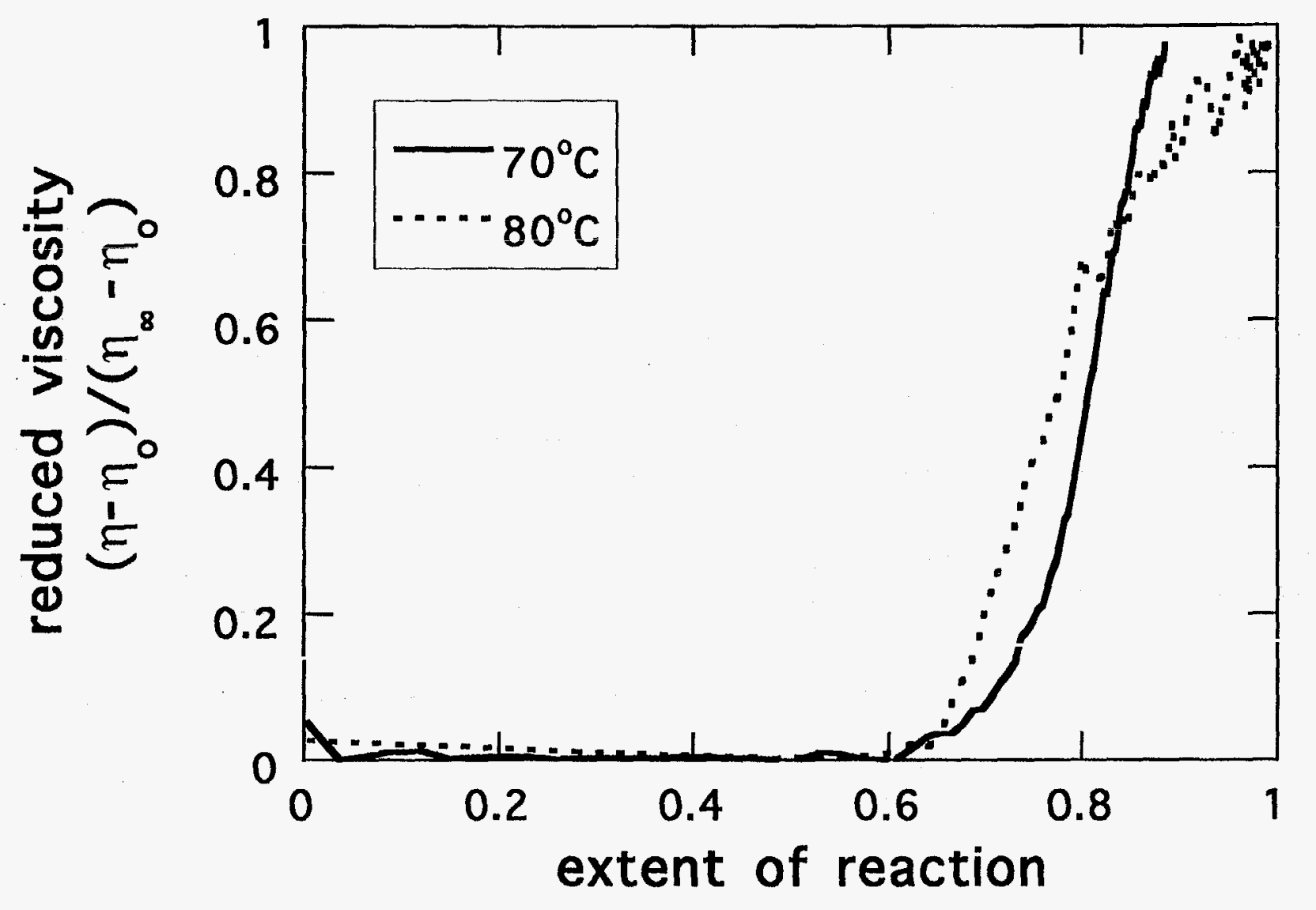


where $\varepsilon=\frac{\mathrm{p}_{\mathrm{g}}^{2}-\mathrm{p}^{2}}{\mathrm{p}_{\mathrm{g}}^{2}}$

and $\log \frac{\eta\left(0, T-T_{g}\right)}{\eta(0,0)}=\frac{-C_{1}\left(T-T_{g}\right)}{C_{2}+T-T_{g}}$

with $\mathrm{T}_{\mathrm{g}}=\frac{\mathrm{T}_{\mathrm{g}}^{\mathrm{O}}}{1-\mathrm{Ap}}$

It is probably useful, if not necessary, to explain each of the terms in Eq.'s 4-7. $\eta(p, T)$ is the quantity of interest, the epoxy shear viscosity at temperature $\mathrm{T}$ and extent of reaction $\mathrm{p}$. The dependence on extent of reaction arises from two factors: (1) the crosslinking reaction increases the average molecular weight of the sol which, in turn, increases the viscosity and (2) the glass transition temperature, $\mathrm{T}_{\mathrm{g}}$, increases with extent of reaction as described by Eq. 7 [ $\mathrm{T}_{\mathrm{g}}{ }^{\circ}$ is the $\mathrm{T}_{\mathrm{g}}$ of the unreacted but mixed reactants]. The $\varepsilon^{-4 / 3}$ term in Eq. 4 captures this first effect. Note that at the gel point, $\mathrm{pg}$, this term diverges, which is qualitatively correct. However, it is quantitatively correct only at constant $\mathrm{T}-\mathrm{T}_{\mathrm{g}}$. For example, even the unreacted epoxy would exhibit a divergent viscosity as we cool and it vitrifies. We described this temperature dependence of the unreacted epoxy by Eq. 1. We have experimentally determined that this relationship also holds during cure if we account for the changing $T_{g}$. We, therefore, need to modify the $\varepsilon^{-4 / 3}$ term by the factor $\eta\left(0, T-T_{g}\right)$ in Eq. 6 , which gives the temperature dependence of the viscosity as it deviates from the current glass transition temperature. To simplify nomenclature, we choose the WLF reference temperature to be the current $T_{g} \cdot \eta(0,0)$, then, is the viscosity of the initial reactants at the unreacted glass transition temperature. The constants in Eqs. 4-7 for our epoxies are presented in Table 3 
Table 3

$\begin{array}{lcccccc}\text { epoxy system } & \underline{p}_{\mathrm{g}} & \underline{\mathrm{\eta}(0,0)(\mathrm{P})} & \underline{\mathrm{C}}_{1} & \left.\underline{\mathrm{C}_{2}(\mathrm{o}} \underline{\mathrm{C}}\right) & \mathrm{T}_{\mathrm{g}} \mathrm{O}_{-}(\mathrm{OK}) & \underline{\underline{\mathrm{A}}} \\ \text { 828/DEA } & 0.65 & 1 \times 10^{10} & 14.2 & 40.4 & 260 & 0.2 \\ 828 / \mathrm{Z} & 0.75 & 7 \times 10^{7} & 12.4 & 43.8 & 260 & 0.25\end{array}$

Tables 3 and 1 predict identical behavior for the unreacted epoxy. Table 1 employs the more convenient reference temperature of $70^{\circ} \mathrm{C}$ when dealing only with the unreacted epoxies, while Table 3 uses the more convenient current $1 \mathrm{~g} g$ when dealing with arbitrary extent of reaction $\left(-13{ }^{\circ} \mathrm{C}\right.$ for the unreacted epoxy). The reference temperature affects the values of $C_{1}$ and $C_{2}$ in the following manner

$$
\begin{aligned}
& C_{2}^{\text {new }}=C_{2}^{\text {old }}+T_{\text {new }}-T_{\text {old }} \\
& C_{1}^{\text {new }}=\frac{C_{1}^{\text {old }} C_{2}^{\text {old }}}{C_{2}^{\text {ne' }} \cdot \frac{2}{}}
\end{aligned}
$$

which we can use to accord Tables 1 and 3.

Obviously, these equations require a knowledge of the increase in extent of reaction with time. The reaction rates for $828 / \mathrm{Z}$ and $828 / \mathrm{DEA}$ from 55 to $100 \mathrm{C}$ are respectively given by

$$
\begin{aligned}
& \frac{\mathrm{dp}}{\mathrm{dt}}=\mathrm{k}\left(0.11+\mathrm{p}^{1.2}\right)(1-\mathrm{p})^{1.35} \\
& \text { with } \mathrm{k}=\left(1.2 \times 10^{6} \mathrm{~min}^{-1}\right) \mathrm{e}^{-(12000 \mathrm{cal} / \mathrm{mole}) / \mathrm{RT}}
\end{aligned}
$$

and 


$$
\frac{\mathrm{dp}}{\mathrm{dt}}=\left(\mathrm{k}_{1}+\mathrm{k}_{2} \mathrm{p}^{\mathrm{m}}\right)(1-\mathrm{p})^{1.6}
$$

with $\mathrm{k}_{1}=\left(2.6 \times 10^{7} \mathrm{~min}^{-1}\right) \mathrm{e}^{-\mathrm{E} / \mathrm{RT}} \quad \mathrm{E}=15.9 \mathrm{kcal} / \mathrm{mole}$

and for $\mathrm{T}<65 \mathrm{C} \quad \mathrm{m}=2$ and $\mathrm{k}_{2}=\left(5.7 \times 10^{8} \mathrm{~min}^{-1}\right) \mathrm{e}^{-\mathrm{E} / \mathrm{RT}}$ for $65 \mathrm{C}<\mathrm{T}<90 \mathrm{C} \quad \mathrm{m}=74 \mathrm{k}_{2}$ where

$$
\mathrm{k}_{2}=\left(9 \times 10^{7} \min ^{-1}\right)\left(\frac{90-\mathrm{T}\left(\text { in }^{\circ} \mathrm{C}\right)}{\mathrm{T}\left(\text { in }^{\circ} \mathrm{C}\right)}\right)
$$

for $\mathrm{T}>90 \mathrm{C} \quad \mathrm{m}=\mathrm{k}_{2}=0$

The complex phenomenological description of the 828/DEA rate in Eq. 9 reflects the equally complex chemical mechanisms of this crosslinking reaction.

\section{Filler Effects}

\section{A. Glass microballoons}

Since Sandia only uses filled epoxies, the dependence of viscosity upon filler fraction is required. At $70^{\circ} \mathrm{C}$, we investigated all commonly used fillers: glass microballoons (GMB), tabular alumina (Alox), $\beta$ eucryptite ( $\beta-\mathrm{eu})$, and a rubber (CTBN) toughened version of GMB. In addition, three types of $3 \mathrm{M} \mathrm{GMB}$ were studied: D32, our current version, with nominal particle diameter of $35 \mu$ and a methacrylatochromic chloride (MCC) antistatic coating; A20 with nominal particle diameter of $60 \mu$ and MCC coating; and H50 with nominal particle diameter of $30 \mu$ and a epoxy silane coupling agent coating. $\mathrm{A} 2 \mathrm{O}$ and $\mathrm{H} 50$ allow us to investigate the effects of particle size and coating independently. Table 4 lists the filler weights used to obtain the various filler volume fractions for all filler systems, based on 100 parts by weight epoxy (density $=1.2 \mathrm{~g} / \mathrm{cc}$ ). 
Table4

filler filler volume fraction filler density $(\mathrm{g} / \mathrm{cc}$ ) weight parts of filler D32 0.30

0.32

11

D32

0.40

0.32

18

D32

0.48

0.32

25

D32

0.55

0.32

33

D32

0.60

0.32

40

A20

0.48

0.20

15

H50

0.48

0.50

38

Alox

0.37

3.98

200

Alox

0.43

3.98

250

Alox

0.48

3.98

300

$\beta$-eu

0.37

2.37

115

$\beta$-eu

0.43

2.37

150

$\beta$-eu

0.48

2.37

CTBN/D32

0.30

0.32

185

CTBN/D32

0.40

0.32

11

CTBN/D32

0.48

0.32

The D32 GMB exhibited no intrinsic time dependence, as seen by a sharp rise to a steady state viscosity in response to a constant shear rate and by reversible behavior in response to increasing or decreasing shear rate ramps. Additiorally, D32 exhibited almost Newtonian behavior with only a hint of shear-thickening at 48 vol.\%, as seen in Fig. 6. Fig. 7 shows that $\mathrm{A} 20$ and $\mathrm{H} 50$ are slightly more viscous and shear-thickening at 48 vol.\%. We originally thought that $\mathrm{H} 50$, with its epoxy coating might be less viscous and easier to process, but no such luck. It actually showed the highest viscosity. 


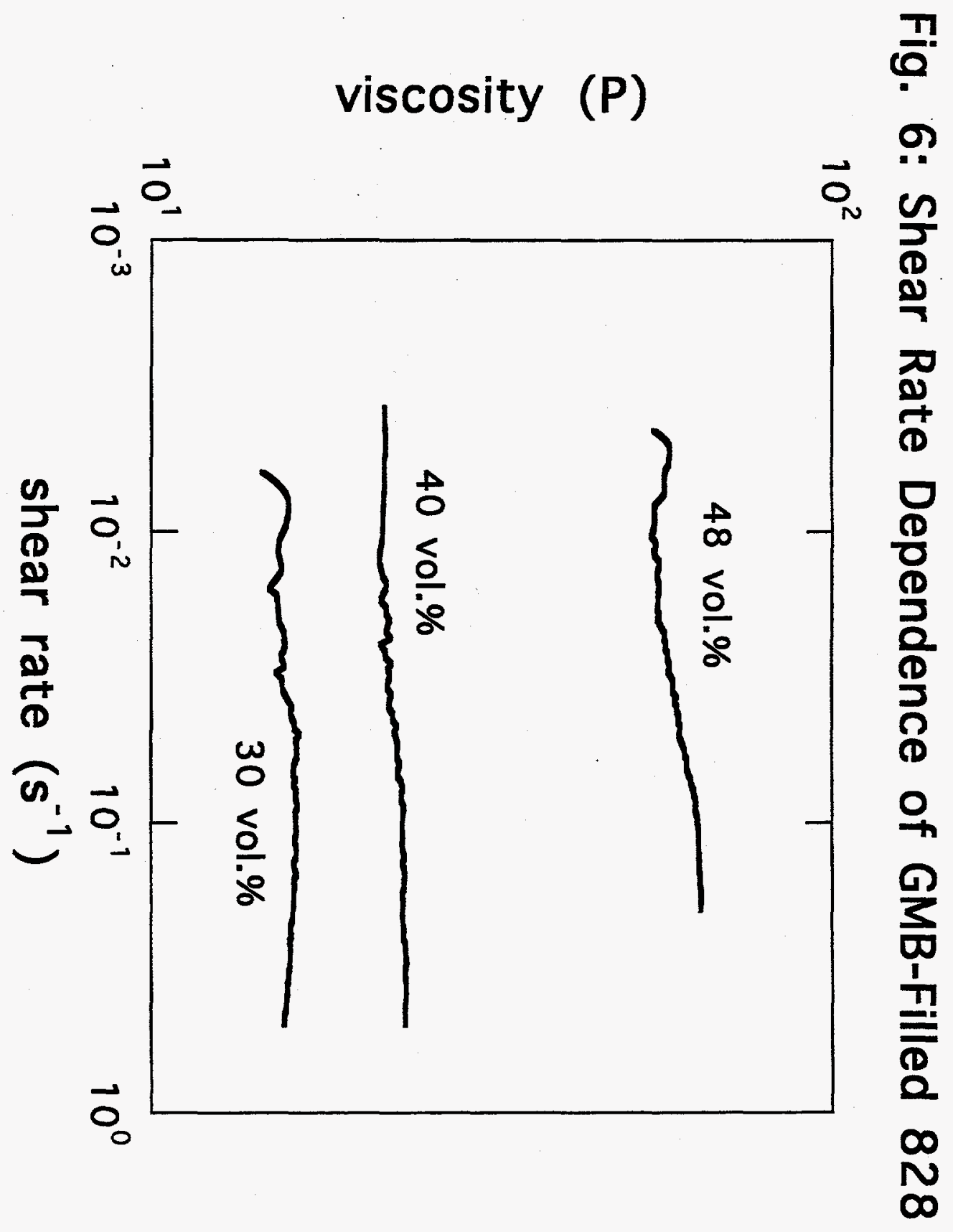




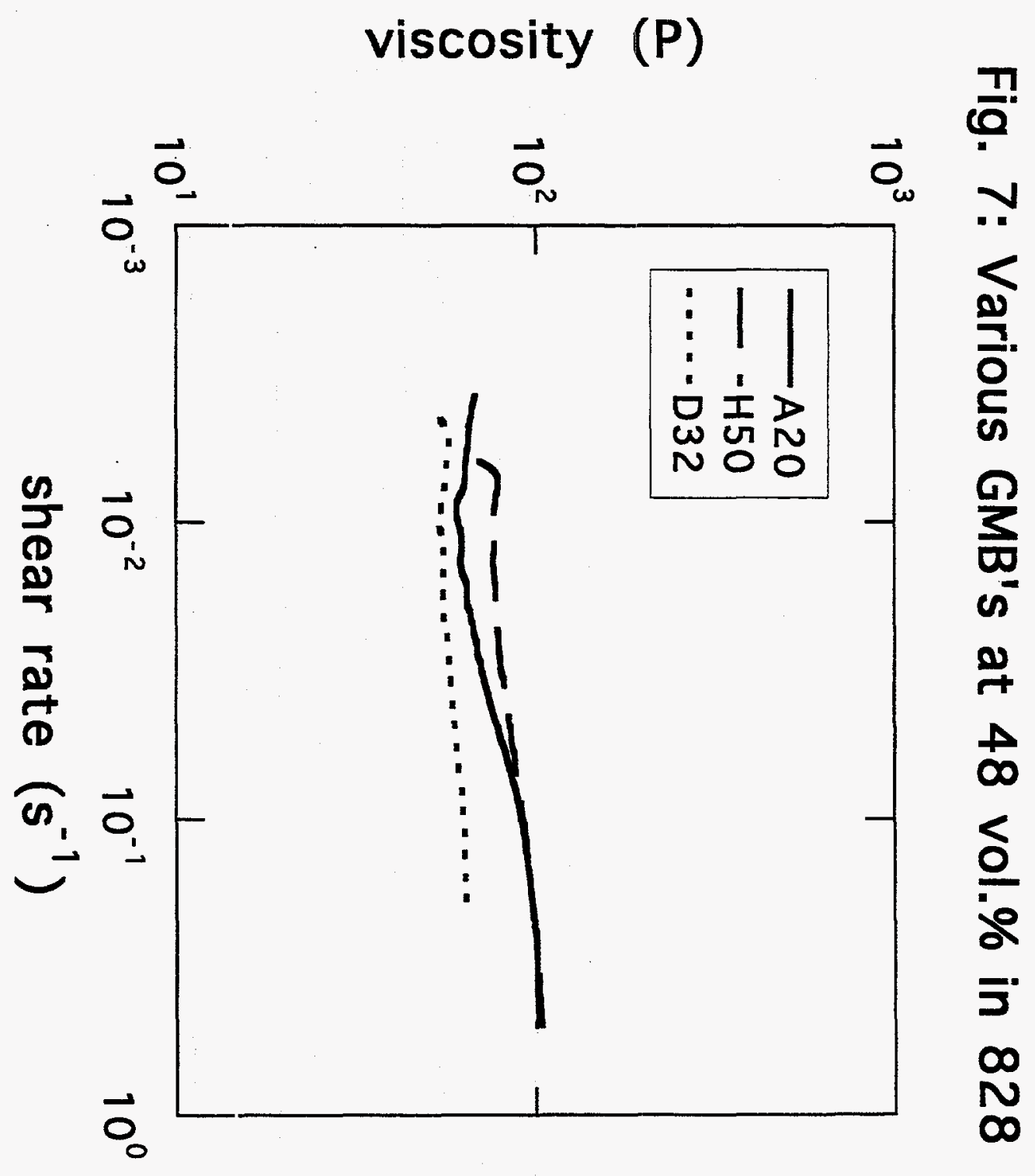




\section{B. Alumina and $\beta$-Eucryptite}

Alox exhibited definite time and shear rate dependencies. In Fig. 8, we show the approach to steady state in response to constant shear rates for a 48 vol.\% suspension. In Fig. 9, we plot the steady state viscosity and time to achieve this value as a function of shear rate for the three different Alox volume fractions. The time to reach steady state is roughly inverselyproportional to the shear rate, $\tau \sim \dot{\gamma}-1$, and the steady state viscosity is definitely shear thickening. That Alox is so different from GMB is not surprising since tabular alumina is a very polydisperse blend of irregular plate-like particles. GMB, by contrast, are extremely smooth spheres and much more mondisperse (particles can still vary easily by a factor of two in radius). From Fig. 9, we can attempt to estimate limiting viscosities at both low and high shear rates. In Fig. 10, we see that these two values are quite distinct. Our typical processing rates, of course, lie somewhere in the transition zone.

Also disturbing is the lot-to-lot variation in Alox viscosities. These are shown in Fig. 11 where we can observe a factor of two difference in the worst case. Previous investigations have attributed these variations to either moisture or particle size. For whatever reason, a difference of two can make these highly filled suspensions unprocessable.

In Fig. 12, we see similar behavior from the $\beta$-eu filler. It is perhaps easier to estimate the low shear rate limiting viscosities, but impossible to estimate the high rate limits. The $\beta$-eu density of $2.37 \mathrm{~g} / \mathrm{cc}$ was obtained by helium pycnometry, ${ }^{2}$ and electron microscopy ${ }^{3}$ clearly shows that the particulates are even more plate-like than Alox, perhaps leading to the more pronounced shear-thickening behavior.

\section{Rubber Toughener and General Filler Trends}

In Fig. 13, we show all the dependencies of viscosity on filler volume fraction at $70^{\circ} \mathrm{C}$ in the low shear rate [Newtonian] limit, including that for 


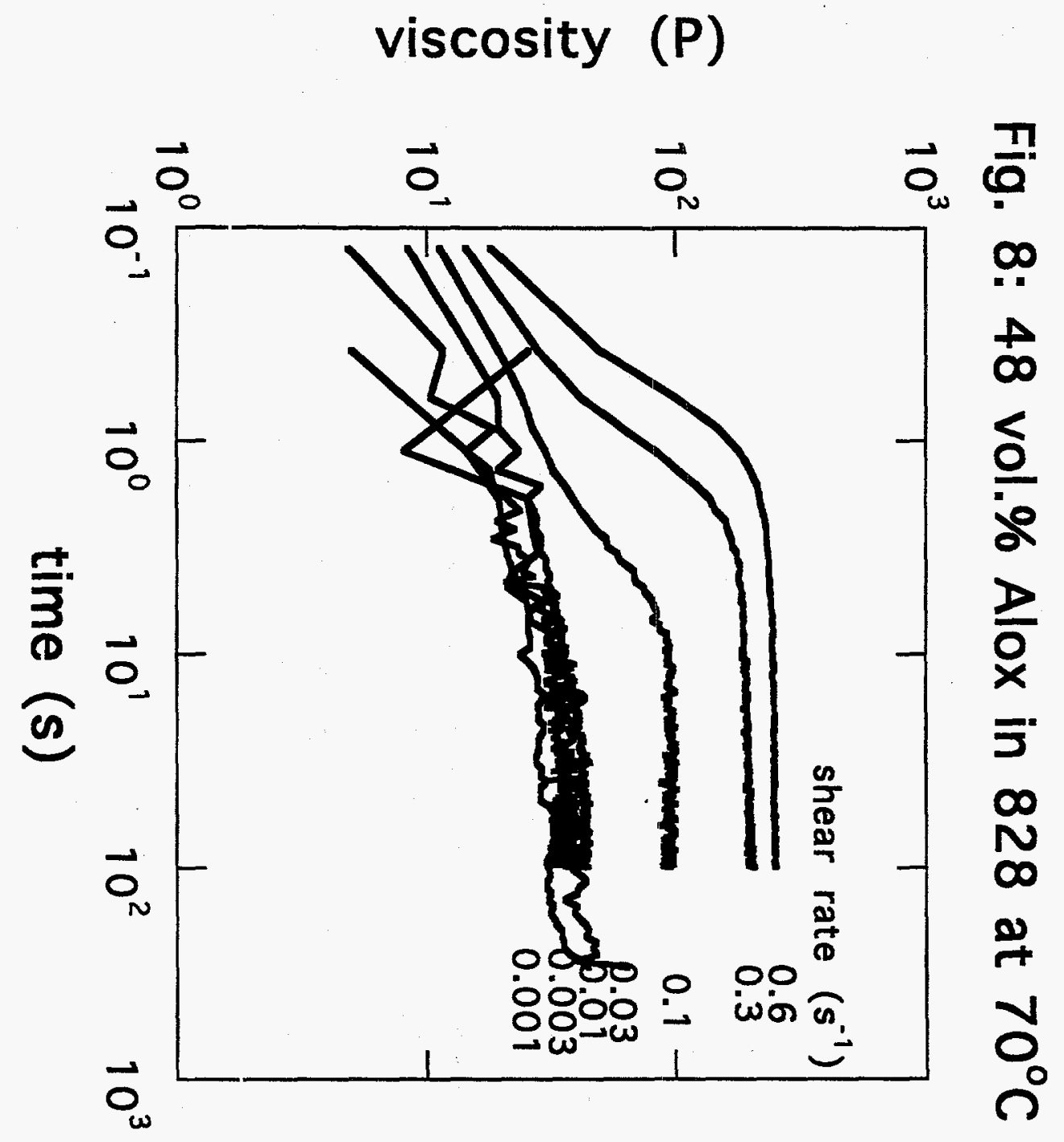




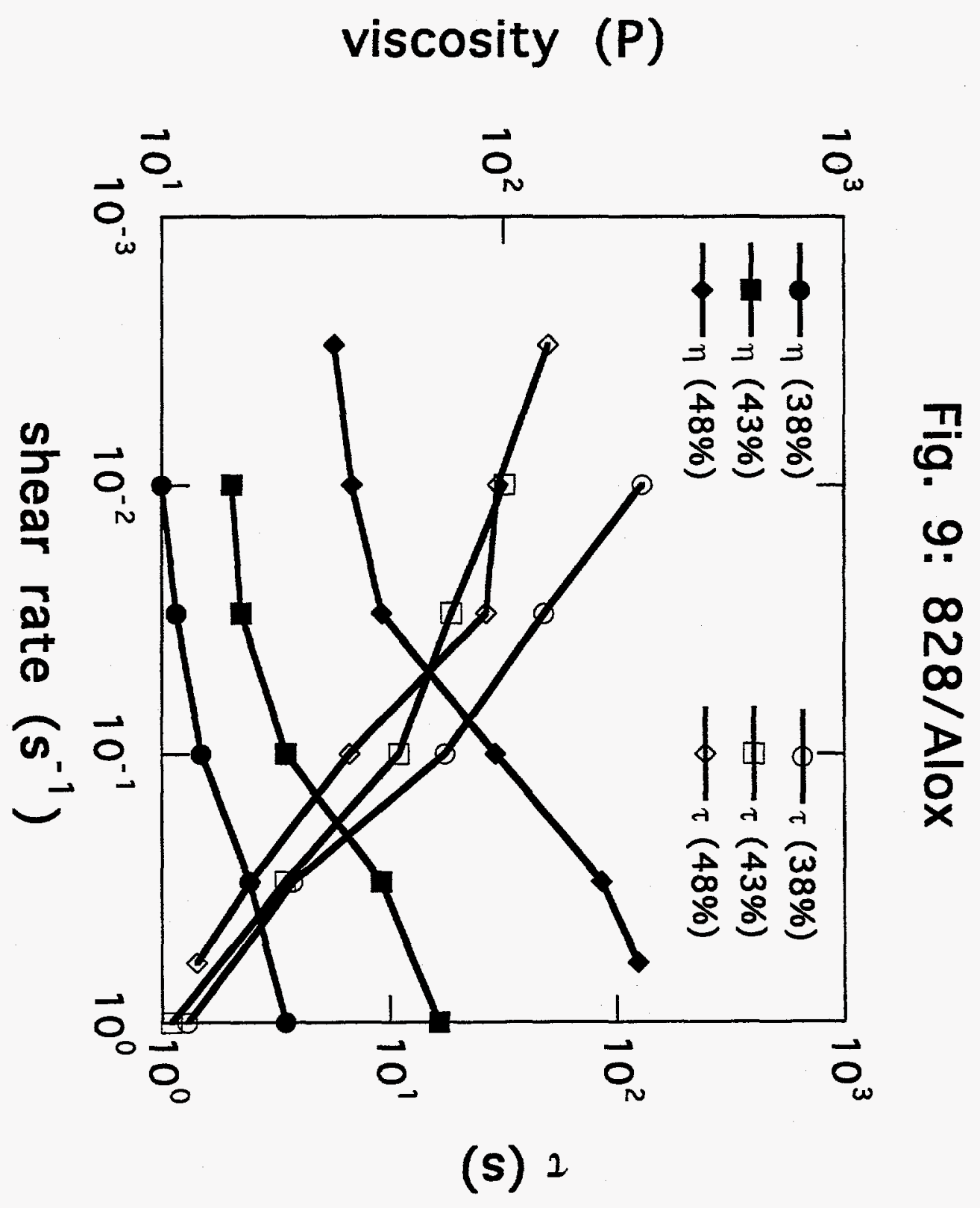




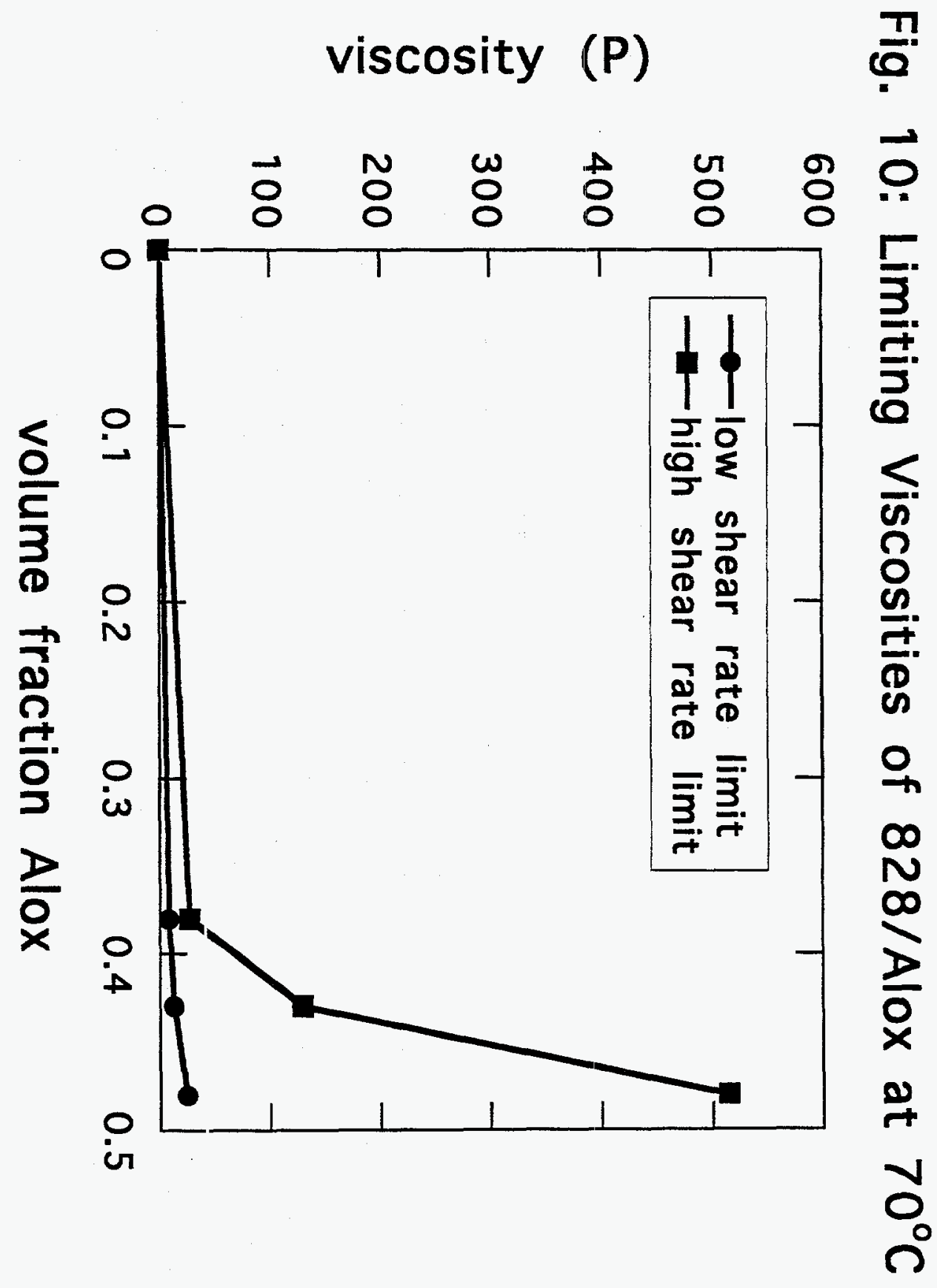


Fig. 11: Various Lots of Alox $\left(48\right.$ vol. $\%$ at $\left.78^{\circ} \mathrm{C}\right)$

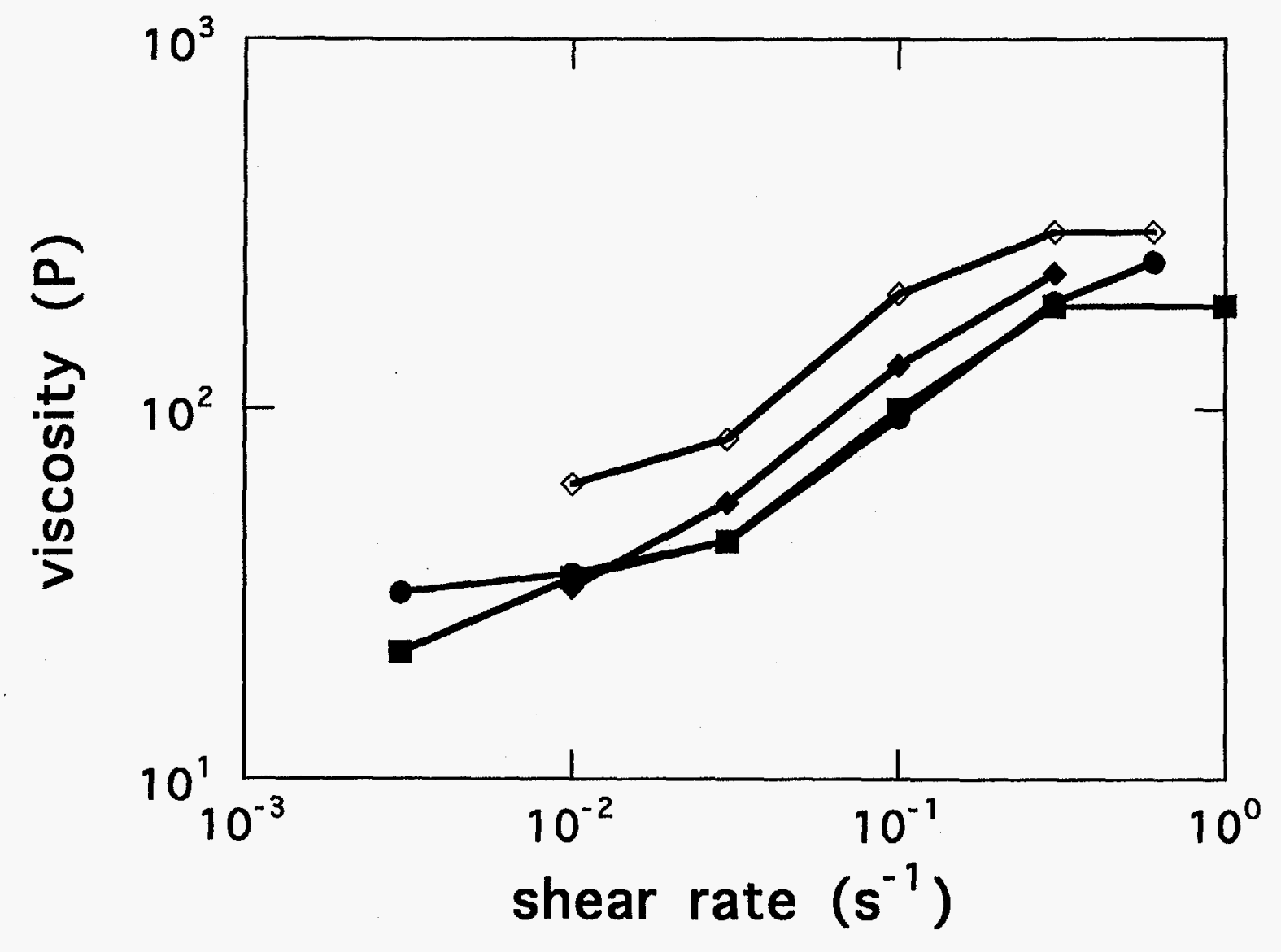




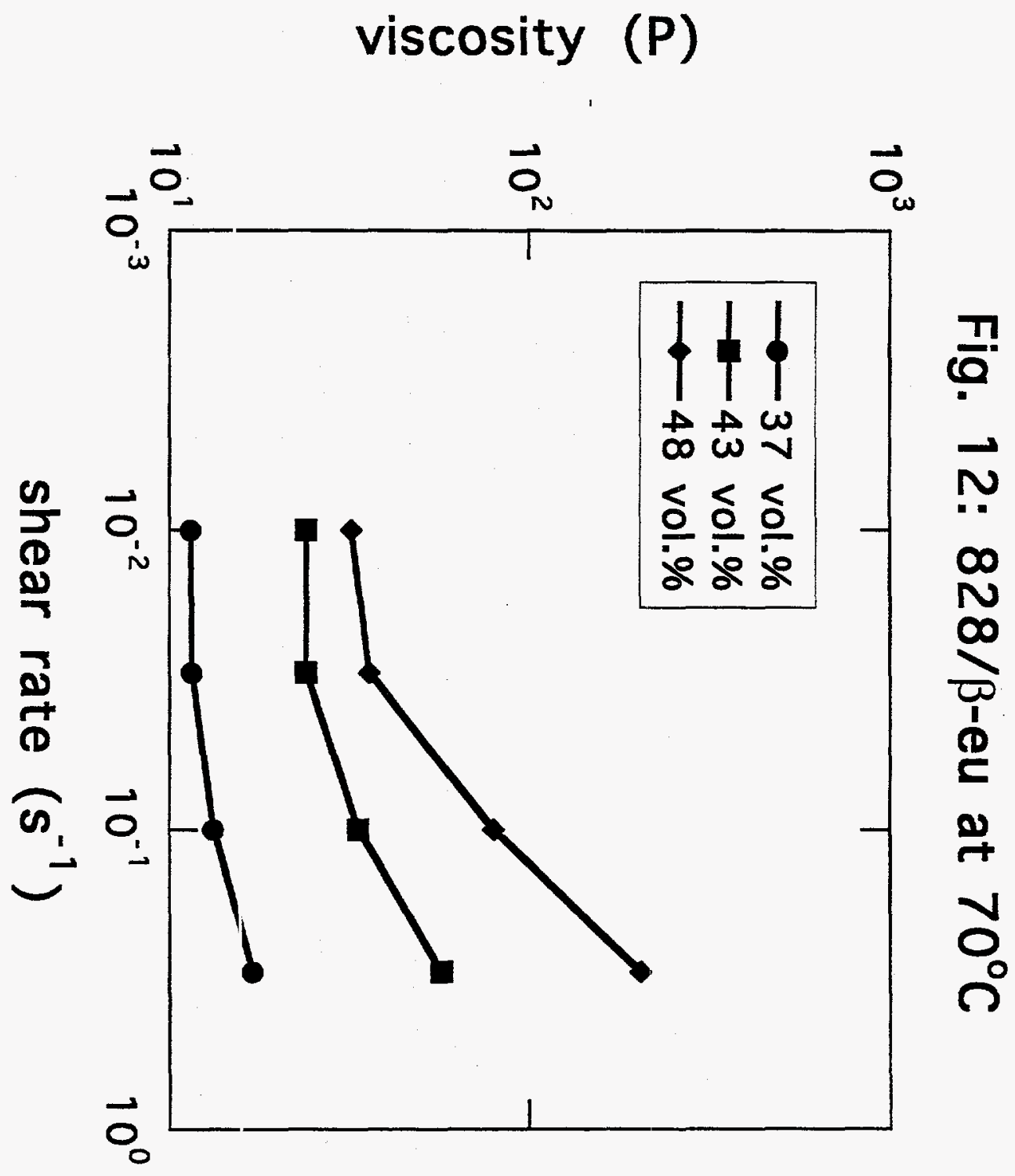


Fig. 13: Comparison of Various Fillers at $70^{\circ} \mathrm{C}$

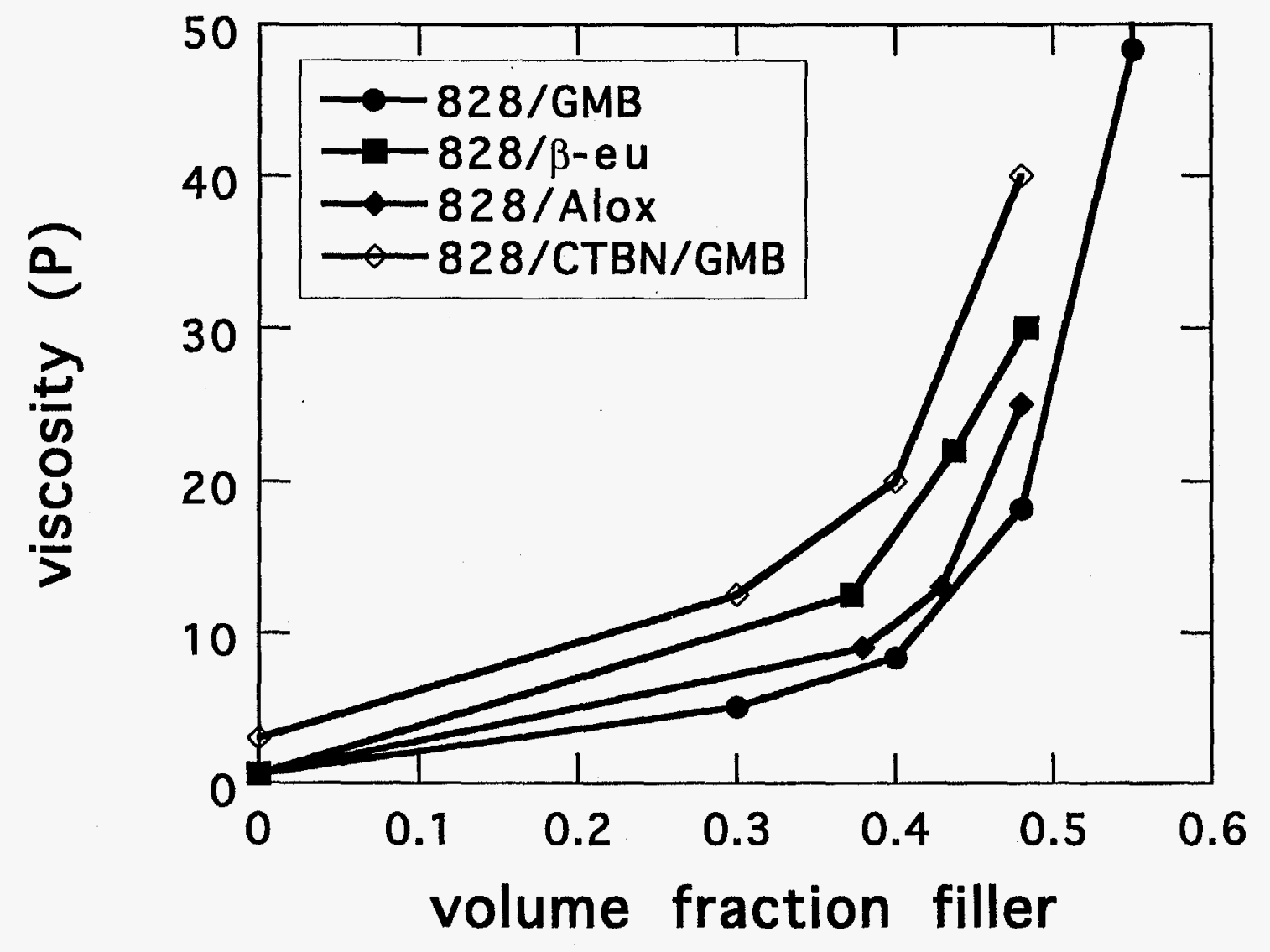


828/CTBN filled with D32 GMB. The trends are not surprising: (1) all viscosities increase sharply with loading levels at volume fractions around $40 \%$ and (2) the $828 / C T B N$ filled resin exhibits the highest viscosity [from Table $1,828 / \mathrm{CTBN}$ is 5 times more viscous than 828 alone at $70^{\circ} \mathrm{C}$ ] followed by 828 with plate-like fillers, $\beta$-eu and Alox.

The same data are replotted in Fig. 14. The ordinate, now plotted logarithmically, is the reduced viscosity, the measured viscosity normalized by the resin [ 828 or $828 / \mathrm{CTBN}]$ viscosity. Interestingly, the $828 /$ CTBN/GMB system, while exhibiting the highest actual viscosity, shows the weakest dependence on filler volume fraction, and is quite distinct from $828 / G M B$. The source of this difference is mysterious. Not as mysterious is the observed stronger dependence of the viscosity for the plate-like fillers on volume fraction.

\section{V.Applications}

A. Mixing/ degassing/pouring during DEA adduct formation

We will now step through two examples that show how the above data can be used to aid production. In the first example, we will examine the mixing/degassing/pouring of 828/DEA/GMB. By mixing, we mean the addition and stirring of the DEA to the $828 / G M B$ suspension, which implies we will be following the viscosity rise during DEA adduct formation. In current processing schedules, the temperature during degassing is not controlled and is free to rise due to reaction exotherm. Moreover, pouring is begun after the peak exotherm $\left(\sim 100^{\circ} \mathrm{C}\right)$ and can continue until the pot cools to below $70^{\circ} \mathrm{C}$. One wonders if processing ease and reproducibility could be improved if pouring is postponed until adduct formation is complete, before significant gelation proceeds, and at a controlled temperature which yields a lower viscosity than observed at $70{ }^{\circ} \mathrm{C}$ under current processing. 4 
Fig. 14: Comparison of Various Fillers at $70^{\circ} \mathrm{C}$

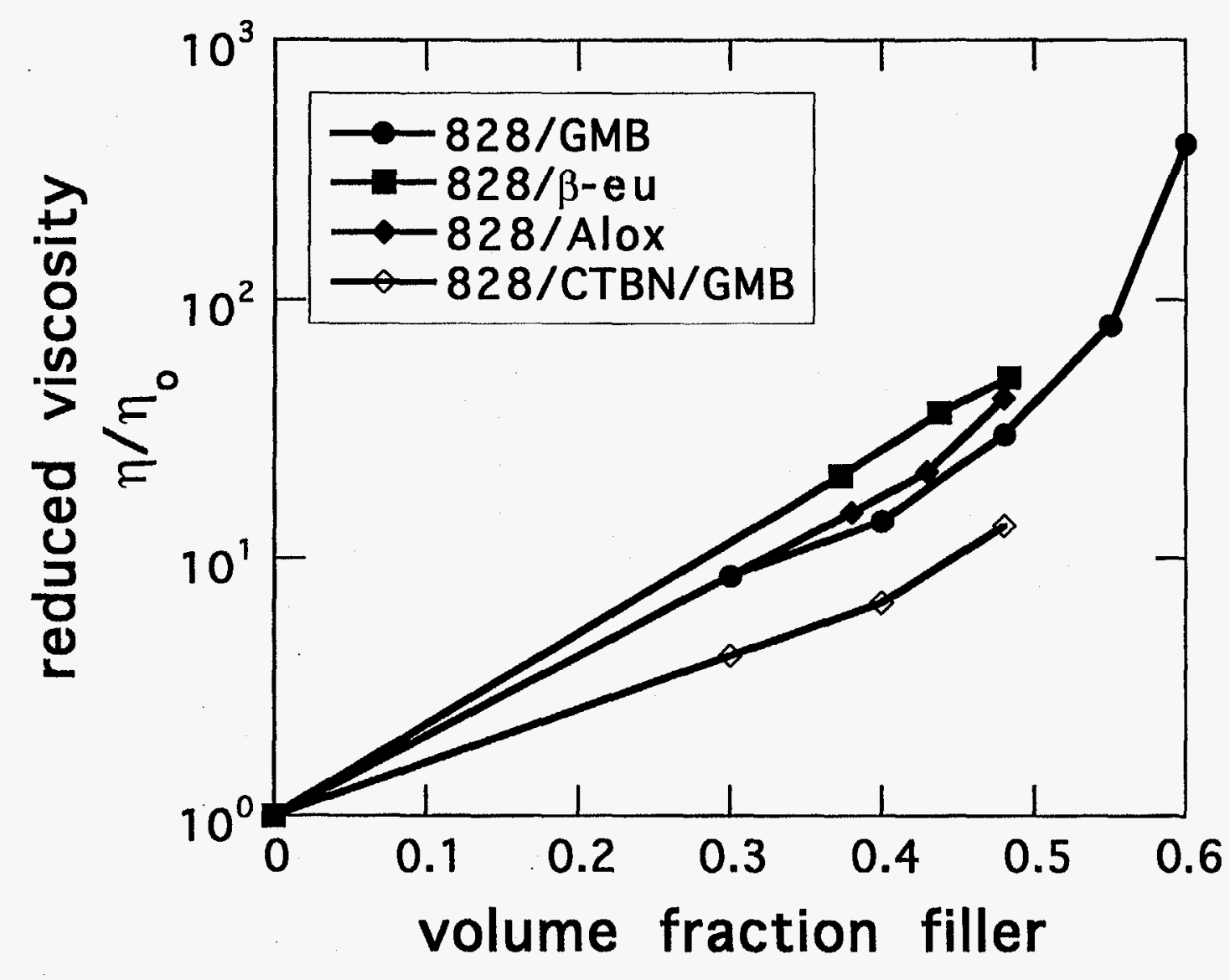


Since our processing window of interest is roughly 20 minutes, Fig. 3 implies that we need only consider the viscosity increase due to adduct formation. The calculations for the viscosity of the current process proceed as follows: (1) prescribe the processing temperature history [this history, in principle, could be calculated with thermal finite element codes using our knowledge of chemical kinetics, heat of reaction, mixing vessel dimensions, and thermal boundary conditions, but for these calculations, we simply assumed a reasonable profile], (2) calculate the adduct formation extent of reaction using Eq. 2, (3) find the reduced viscosity at this extent of reaction from Fig. 5, (4) use Eq. 1 to calculate the actual viscosity at the current temperature [ $\eta_{\infty}$ corresponds to the 828/DEA viscosity of Table 1 while $\eta_{\mathrm{o}}$ corresponds to the viscosity of 828 alone], and (5) increase the viscosity by the GMB volume fraction enhancement factor found in Fig. 14. [In the following calculations, we actually neglected this last step which simply renormalizes the viscosity, and simply followed the 828/DEA viscosity rise.]

Fig. 15 shows the increase in viscosity of $828 /$ DEA during adduct formation under the current processing schedule for which the processing temperature reaches a maximum of $100^{\circ} \mathrm{C}$. At 17.5 minutes at which the temperature is $70 \mathrm{OC}_{\mathrm{C}}$, the viscosity is $2.25 \mathrm{P}$. From Fig. 3, we see that the adduct reaction is almost complete, and from Table 1, we see that the viscosity at adduct completion for $70^{\circ} \mathrm{C}$ equals $2.6 \mathrm{P}$. The predicted value of $2.25 \mathrm{P}$ seems reasonable. Again from Table 1, we see that the viscosity at $80^{\circ} \mathrm{C}$ for complete adduct formation [ 15 minutes from Fig. 3] equals 1.25 $P$. Therefore, we conclude that it might be advantageous to postpone pouring for 20 minutes after adding DEA but pour at a controlled temperature of $800 \mathrm{C}$. This new schedule has the apparent advantages of improved flow [reduced viscosity] and enhanced reproducibility [pouring occurs after exotherm under a controlled temperature]. 


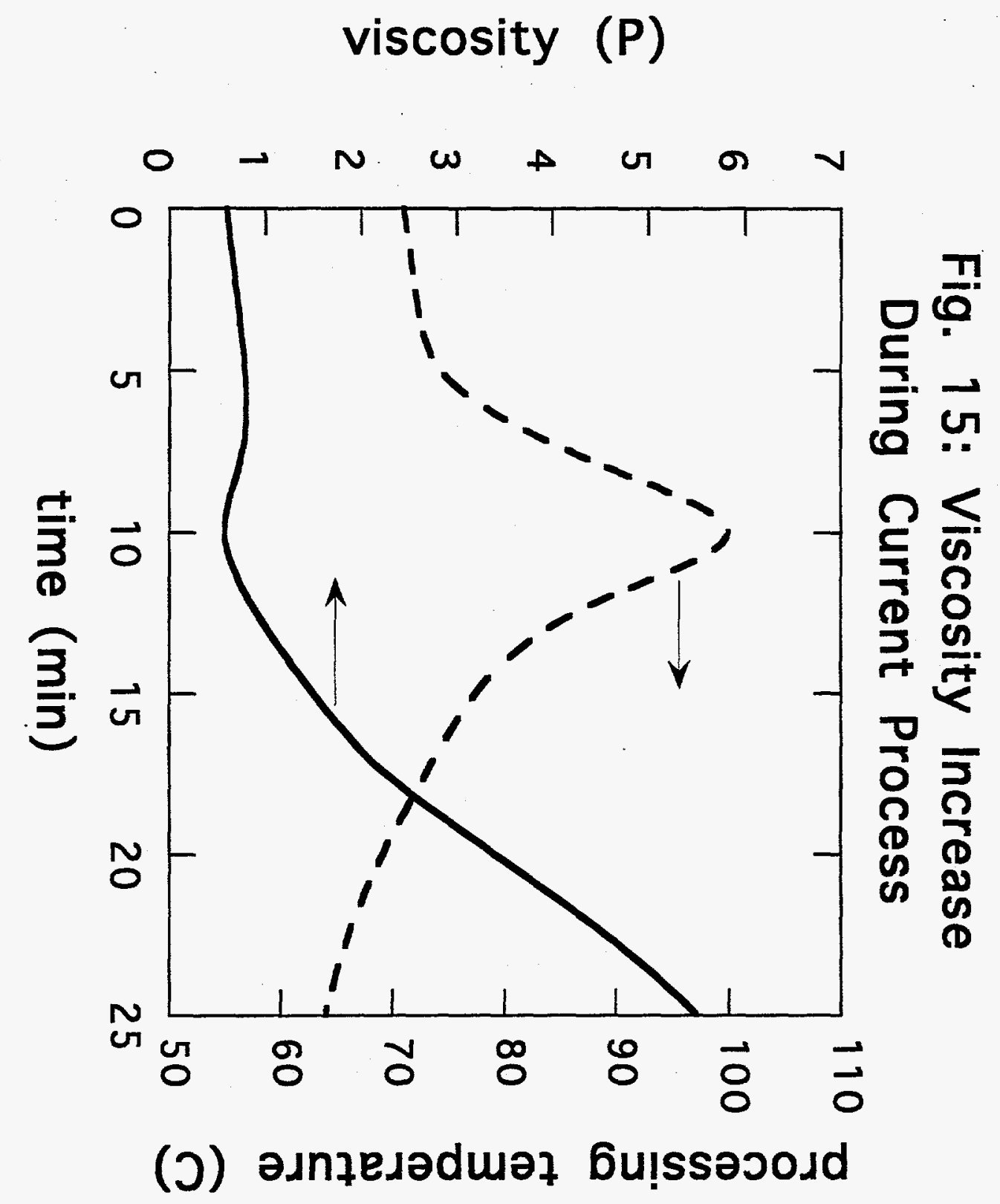


B. 459 potlife

Curing agent " $\mathrm{Z}$ ", a mixture of aromatic amines, is carcinogenic. The current replacement, "459", employs a mixture of aliphatic amines. It cures somewhat faster than $Z$, however, which increases the viscosity faster under the standard processing schedule (nominally, a $71^{\circ} \mathrm{C}$ isothermal cure) and results in reduced "pot life". In this second example, then, we wish to find an isothermal processing schedule for 459 which yields a potlife similar to $Z$. We will operationally define potlife by the viscosity attained by $\mathrm{Z}$ in one hour at $71{ }^{\circ} \mathrm{C}$ and will, therefore, determine at which temperature does 459 attain this same viscosity in roughly one hour.

In Fig. 16, we show the increase in viscosity of $828 / \mathrm{Z}$ as it cures at $71^{\circ} \mathrm{C}$ over an hour. We first used Eq. 9 to calculate the extent of reaction as a function of time, and then, from Eqs. 4-7, calculated the viscosity increase. The same procedure was used for 459 with

$$
\begin{aligned}
& \frac{\mathrm{d} p}{\mathrm{dt}}=\mathrm{k}(0.367+\mathrm{p})(1-\mathrm{p})^{1.5} \\
& \text { with } \mathrm{k}=\left(1.9 \times 10^{6} \mathrm{~min}^{-1}\right) \mathrm{e}^{-(12000 \mathrm{cal} / \mathrm{mole}) / \mathrm{RT}}
\end{aligned}
$$

and

$\begin{array}{cccccc}\mathrm{pg}_{\mathrm{g}} & \underline{\mathrm{\eta}(0,0)(\mathrm{P})} & \underline{\mathrm{C}_{1}} & \underline{\mathrm{C}_{2}(\mathrm{O}} \underline{\mathrm{C})} & \underline{\mathrm{T}}_{\mathrm{g}} \mathrm{O}_{-}(\mathrm{O} \mathrm{OK}) & \underline{\mathrm{A}} \\ 0.865 & 1.5 \times 10^{7} & 12.4 & 43.8 & 260 & 0.29\end{array}$

Fig. 16 also shows the 459 viscosity increase under isothermal cures at 71 , 63 , and $54^{\circ} \mathrm{C}$. At $54^{\circ} \mathrm{C}$, the reaction is sufficiently slowed that pot life is similar to $828 / Z$. Production scale tests confirm these calculations. 
Fig. 16: Isothermal Processing Schemes for $828 / Z$ and 459

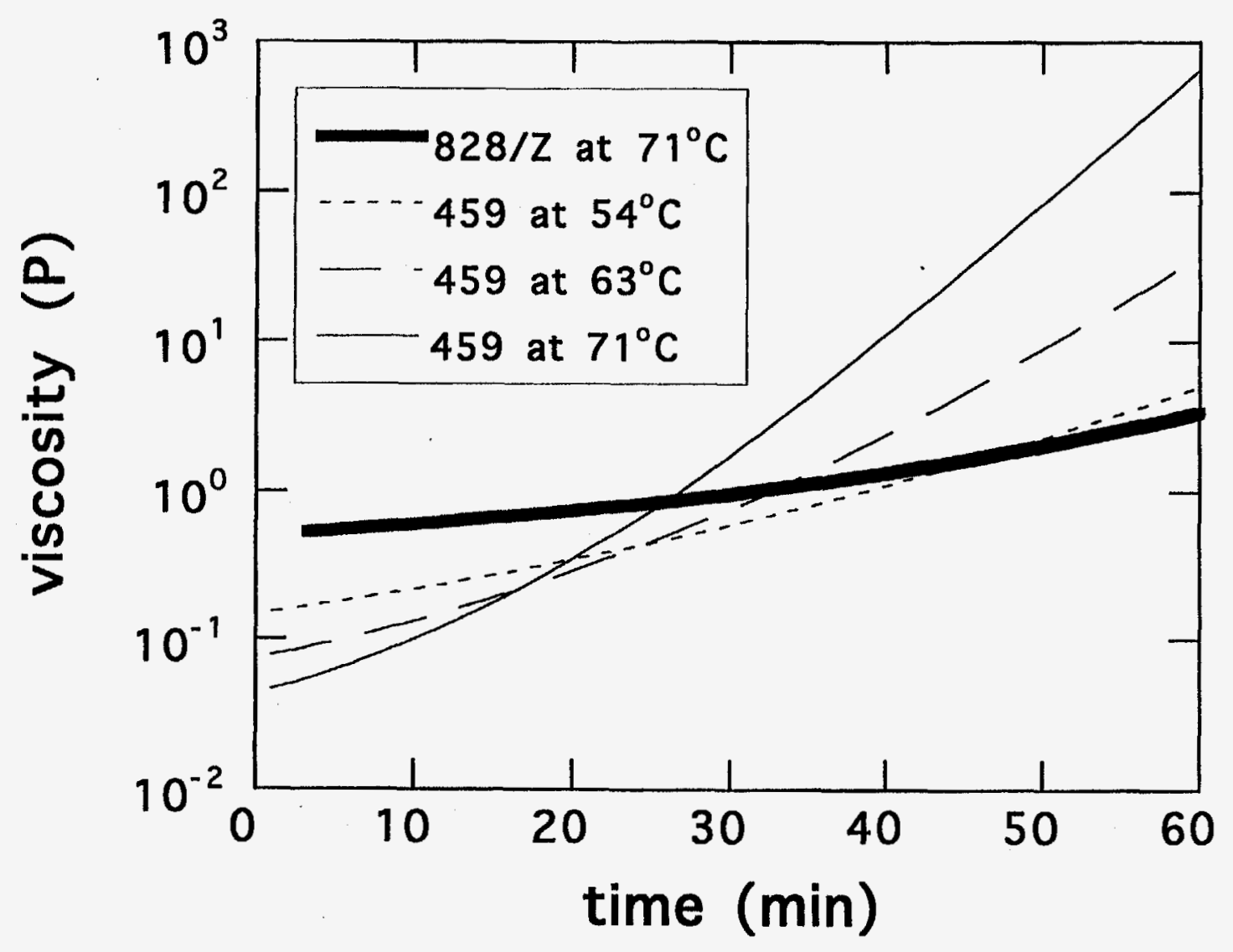


VI. References and Acknowledgements

(1) D. Adolf and J. E. Martin, "Evolution of Structure and Viscoelasticity in Diethanolamine-Cured Epoxy", Sandia Report SAND90-0217, 1990.

(2) Thanks to Bob Lagasse and John Schroeder, 1815.

(3) Thanks to Bonnie McKenzie, 1822.

(4) From Matt Donnelly, 1472. 


\begin{tabular}{|c|c|c|}
\hline 1 & MS9018 & Central Technical Files, 8940-2 \\
\hline 5 & 0899 & Technical Library, 4916 \\
\hline 2 & 0619 & $\begin{array}{l}\text { Review \& Approval Desk, } 12690 \\
\text { For DOE/OSTI }\end{array}$ \\
\hline 10 & 0333 & Doug Adolf, 1841 \\
\hline 5 & 0753 & Roger Strommen, 6218 \\
\hline 1 & 0333 & Harry Johnson, 1841 \\
\hline 1 & 0961 & John Sayre, 1403 \\
\hline 1 & 0958 & Carol Adkins, 1472 \\
\hline 1 & 0958 & Matt Donnelly, 1472 \\
\hline 1 & 0958 & John Emerson, 1472 \\
\hline 1 & 0958 & Howard Arris, 1472 \\
\hline 1 & 0958 & Mark Stavig, 1472 \\
\hline 1 & 0515 & Frank Bacon, 1561 \\
\hline 1 & 0342 & Kim Mahin, 1807 \\
\hline 1 & 1407 & Bob Lagasse, 1815 \\
\hline 1 & 0343 & Mike Keenan, 1824 \\
\hline 1 & 0333 & Al Hurd, 1841 \\
\hline 1 & 0328 & Marty Stevenson, 2674 \\
\hline 1 & 9404 & Linda Domeier, 8713 \\
\hline
\end{tabular}




$\begin{array}{lcl}1 & 0826 & \text { Rehka Rao, } 9111 \\ 1 & 0834 & \text { Lisa Mondy, } 9112 \\ 1 & 0443 & \text { Bob Chambers, } 9117 \\ 1 & 0443 & \text { Steve Burchett, } 9117 \\ 1 & 0443 & \text { Hal Morgan, } 9117 \\ 1 & 0856 & \text { Barb Wells, } 14482\end{array}$

